\title{
MODELO PARA ESTIMATIVA DA INFILTRAÇÃO DE ÁGUA E PERFIL DE UMIDADE DO SOLO ${ }^{(1)}$
}

\author{
Roberto Avelino Cecílio ${ }^{(2)}$, Mauro Aparecido Martinez $^{(3)}$, Fernando Falco Pruski $^{(3)}$ \& \\ Demetrius David da Silva ${ }^{(3)}$
}

\begin{abstract}
RESUMO
A adequada modelagem da infiltração de água no solo é fundamental para estimação do movimento de água, erosão hídrica, recarga e contaminação de aquíferos. Este trabalho apresenta um modelo para estimativa da infiltração de água no solo (GAML-c), com base no modelo de Green-Ampt-Mein-Larson, que provê descrição da geometria e do deslocamento da frente de umedecimento no solo. Testes experimentais foram conduzidos em Latossolo Vermelho-Amarelo para avaliar o GAML-c, usando-se quatro diferentes cenários: considerando a condutividade hidráulica do solo igual à taxa de infiltração estável (Tie) e a umidade máxima do solo igual ao teor de água na zona de transmissão $\left(\theta_{\mathrm{w}}\right)$ (TW); condutividade hidráulica do solo igual à do solo saturado $\left(\mathrm{K}_{\mathbf{0}}\right)$ e a umidade máxima do solo igual $\theta_{\mathrm{w}}(\mathrm{KW})$; condutividade hidráulica do solo igual à Tie e a umidade máxima do solo igual ao teor de água na saturação $\left(\theta_{\mathrm{s}}\right)$ (TS); e condutividade hidráulica do solo igual a $K_{0}$ e a umidade máxima do solo igual $\theta_{\mathrm{S}}(\mathrm{KS})$. Verificou-se que o GAML-c no cenário TW foi o melhor estimador do perfil de umidade do solo, resultando em aceitáveis estimativas da infiltração de água.
\end{abstract}

Termos de indexação: condutividade hidráulica, modelo de Green-Ampt-MeinLarson, Latossolo.

SUMMARY: MODEL TO PREDICT WATER INFILTRATION AND SOIL MOISTURE PROFILE

Soil water infiltration modeling is an important tool to predict soil water redistribution, soil erosion, aquifer recharge and aquifer contamination. This paper presents a model to simulate soil water infiltration (GAML-c), based on the Green-Ampt-Mein-Larson (GAML)

(1) Recebido para publicação em 8 de agosto de 2012 e aprovado em 5 de fevereiro de 2013

(2) Professor, DS, Universidade Federal do Espírito Santo, DCFM. Bolsista do CNPq. Alto Universitário, s/n. Caixa Postal 16. CEP 29500000 Alegre (ES). E-mail: roberto.cecilio@ufes.br

(3) Professor, DS, Departamento de Engenharia Agrícola, Universidade Federal de Viçosa. Bolsista do CNPq. Av. P. H. Rolfs, s/n. CEP 36570-000 Viçosa (MG). E-mail: mmauro@ufv.br; ffpruski@ufv.br; david@ufv.br 


\begin{abstract}
model that provides a description of the geometry and advance of the wetting front in the soil. Experimental infiltration tests were performed in Red-Yellow Oxisol (LVA). GAML-c was evaluated in four scenarios: considering hydraulic conductivity $\left(K_{0}\right)$ equal to the stable infiltration rate (Tie) and the maximum soil moisture equal to $\theta_{w}(T W)$; considering the $K_{0}$ value determined by constant-head permeameter method and the maximum soil moisture equal to $\theta_{w}(\mathrm{KW})$; considering $K_{0}$ equal to Tie and the maximum soil moisture equal to $\theta_{s}(T S)$; and considering the $K_{0}$ value determined by the constant-head permeameter method and the maximum soil moisture equal to $\theta_{s}(K S)$. It was verified that for the scenario TW, the GAMLc model was able to simulate the soil water profile and provide satisfactory predictions of infiltration.
\end{abstract}

Index terms: hydraulic conductivity, Green-Ampt-Mein-Larson model, Oxisol.

\section{INTRODUÇÃO}

A demanda por modelos destinados à previsão hidrológica aumenta quando da notificação da ocorrência de enchentes ou degradação ambiental causada por erosão hídrica e contaminação dos recursos hídricos superficiais e subterrâneos. O desenvolvimento de modelos hidrológicos eficientes, entretanto, requer esforço contínuo de pesquisa, sendo necessárias informações consistentes sobre os processos do ciclo hidrológico, do clima, da topografia e do solo, dentre outras.

Nesse contexto, destaca-se a necessidade de adequada estimativa do processo de infiltração para a modelagem do movimento de água no solo (Wang et al., 2009); das perdas de solo e água, decorrentes de processos erosivos (Nearing et al., 2011); e da recarga ou contaminação de aquíferos (Wang et al., 2012).

A infiltração é o processo de passagem da água da superfície para o interior do solo; o aumento dessa pode acarretar em redução da erosão e maior recarga dos aquíferos, ampliando o escoamento de base e reduzindo as vazões máximas de cursos d'água. Para boa modelagem desse processo, é necessário o entendimento de suas relações com as propriedades do solo. Entretanto, a caracterização das variáveis que influenciam na infiltração é demorada e difícil, pois a intensidade com que algumas variáveis influenciam o processo, ainda hoje, não é bem definida.

Dentre os modelos existentes para estimativa da infiltração, o de Mein \& Larson (1973), denominado modelo de Green-Ampt-Mein-Larson (GAML), é um dos mais empregados em razão da sua relativa simplicidade e por apresentar bons resultados na estimativa da infiltração (Kale \& Sahoo, 2011). Podem-se destacar, todavia, três limitações para a utilização do modelo GAML: os parâmetros de entrada não representam efetivamente as condições reais de ocorrência da infiltração, pois a frente de umedecimento não é abrupta, não ocorrendo saturação do perfil do solo acima da frente de umedecimento e existindo variação da condutividade hidráulica ao longo do tempo e do perfil do solo; a dificuldade e pouca confiabilidade nas formas de obter esses parâmetros; e a incapacidade de estimar o perfil de umidade do solo durante a infiltração.
Propostas simples para contornar os dois primeiros problemas vêm sendo feitas há décadas por diversos pesquisadores, por meio de métodos para adequar os parâmetros de entrada de GAML. Contudo, muitas dessas propostas baseiam-se em equações empíricas, derivadas de dados experimentais, acabando por não serem aplicáveis em qualquer situação (Cecílio et al., 2007). Também, uma forma de contornar os problemas do modelo GAML consiste na análise físicomatemática mais detalhada do processo de infiltração, especificando condições de contorno mais adequadas (Rucker, 2009; Wang et al., 2009), principalmente para a interface entre o solo umedecido e o solo no teor de água inicial, isto é, a frente de umedecimento.

Pelo exposto, em razão das dificuldades encontradas na aplicação do modelo de GAML, este trabalho teve como objetivos desenvolver e avaliar um modelo para estimativa da infiltração de água no solo, fundamentado em GAML, que possua maior detalhamento físico, levando em consideração o fato de a frente de umedecimento não ser abrupta, de não ocorrer saturação do perfil do solo acima dessa frente e de acontecer variação da condutividade hidráulica ao longo do tempo e do perfil do solo.

\section{MATERIAL E MÉTODOS}

\section{Desenvolvimento do modelo}

O modelo proposto (GAML-c) objetivou estimar a infiltração sob condições de precipitação, baseando-se numa descrição mais aproximada da geometria e do deslocamento da frente de umedecimento. O processo de infiltração é dividido em duas etapas distintas: antes e depois da ocorrência de empoçamento de água sobre a superfície do solo.

\section{Infiltração antes do empoçamento}

Toda água precipitada infiltra no solo, elevando o teor de água inicial $\left(\theta_{\mathrm{i}}\right)$ para o teor de água na saturação $\left(\theta_{\mathrm{s}}\right)$. A frente de umedecimento é considerada como um plano abaixo do qual o teor de água é igual a $\theta_{\mathrm{i}}$ e acima do qual o teor de água é $\theta_{\mathrm{s}}$. 
A lâmina infiltrada antes do empoçamento $\left(\mathrm{I}_{0}\right)$ foi calculada pela equação 1 (Mein \& Larson, 1973). Todavia, para a aplicação dessa equação, foi necessário o conhecimento do potencial matricial na frente de umedecimento $\left(\psi_{\mathrm{f}}\right)$. No GAML-c, considerouse que esse potencial fosse igual ao potencial matricial de entrada de ar $\left(\psi_{\mathrm{b}}\right)$, proposto por Brooks \& Corey (1964).

$$
\mathrm{I}_{0}=\frac{\psi_{\mathrm{f}}}{\frac{\mathrm{i}_{\mathrm{p}}}{\mathrm{K}_{0}}-1}\left(\theta_{\mathrm{s}}-\theta_{\mathrm{i}}\right)
$$

em que: $\mathrm{I}_{0}=$ lâmina infiltrada antes da saturação da superfície, $\mathrm{L} ; \psi_{\mathrm{f}}=$ potencial matricial do solo na frente de umedecimento, $L ; \theta_{\mathrm{s}}=$ teor de água do solo saturado, $\mathrm{L}^{3} \mathrm{~L}^{-3} ; \theta_{\mathrm{i}}=$ teor de água do solo antes do início do processo de infiltração, $\mathrm{L}^{3} \mathrm{~L}^{-3} ; \mathrm{i}_{\mathrm{p}}=$ intensidade de precipitação, $\mathrm{LT}^{-1} ; \mathrm{K}_{0}=$ condutividade hidráulica do solo saturado, $\mathrm{L} \mathrm{T}^{-1}$.

O tempo necessário para o empoçamento foi calculado pela equação 2; nesse intervalo de tempo a taxa de infiltração (Ti) foi igual a $i_{p}$. A profundidade da frente de umedecimento $\left(\mathrm{L}_{0}\right)$ no momento do empoçamento foi dada pela equação 3 :

$$
t_{p}=\frac{I_{0}}{i_{p}}
$$

em que $t_{p}$ foi o tempo de empoçamento da água na superfície do solo, T:

$$
\mathrm{L}_{0}=\frac{\mathrm{I}_{0}}{\theta_{\mathrm{s}}-\theta_{\mathrm{i}}}
$$

\section{Infiltração após o empoçamento}

Nessa fase, o GAML-c considerou que o perfil de umedecimento do solo durante a infiltração foi aquele apresentado na figura 1a. Assim, na zona de saturação, o teor de água no solo foi igual a $\theta_{\mathrm{s}}$. Abaixo dessa, situa-se a zona de transmissão, em que o perfil de solo foi umedecido até o teor de água da zona de transmissão $\left(\theta_{\mathrm{w}}\right)$, menor ou igual a $\theta_{\mathrm{s}}$. Logo após a zona de transmissão, situa-se a frente de umedecimento, onde existe decréscimo gradual do teor de água ao longo da profundidade.

O GAML-c permitiu obter melhor descrição da frente de umedecimento, utilizando-se o conceito de movimento tipo pistão, idealizado em GAML. Para tanto, realizou-se uma discretização do teor de água para o qual o solo foi umedecido, quando houve a ocorrência do processo de infiltração. O GAML-c propôs simular o deslocamento simultâneo de diversas subfrentes de umedecimento pelo perfil do solo, todas se deslocando de acordo com movimento do tipo pistão e elevando o teor de água do solo em um valor fixo igual a Dq (Figura 1b). Esse valor foi calculado pelas equações 4 ou 5 , caso considerasse que a zona de transmissão atingisse ou não a saturação, respectivamente:

$$
\Delta \theta=\frac{\theta_{\mathrm{s}}-\theta_{\mathrm{i}}}{\mathrm{nf}}
$$

em que nf foi o número de subfrentes de umedecimento que se desejou considerar:

$$
\Delta \theta=\frac{\theta_{\mathrm{w}}-\theta_{\mathrm{i}}}{\mathrm{nf}}
$$

Considerou-se que o processo ocorresse da seguinte maneira:

1. Logo após o empoçamento, o deslocamento da primeira subfrente de umedecimento fez com que o teor de água do solo se elevasse de $\theta_{\mathrm{i}}$ para $\theta_{\mathrm{s}}\left(\right.$ ou $\theta_{\mathrm{w}}$, conforme situação considerada);

2. Simultaneamente ao deslocamento dessa primeira subfrente, ocorreu o deslocamento de uma segunda, mais profunda, que elevou o teor de água do solo de $\theta_{\mathrm{i}}$ para $\theta_{\mathrm{s}}-\Delta \theta\left(\right.$ ou $\left.\theta_{\mathrm{w}}-\Delta \theta\right)$;

3. Outras subfrentes de umedecimento também se deslocaram simultaneamente em maiores profundidades, elevando o teor de água do solo a valores decrescentes, até que a última elevou o teor de água para $\theta_{i}+\Delta \theta$, apenas.

Da mesma forma que realizadas na concepção do modelo GAML, algumas premissas foram assumidas
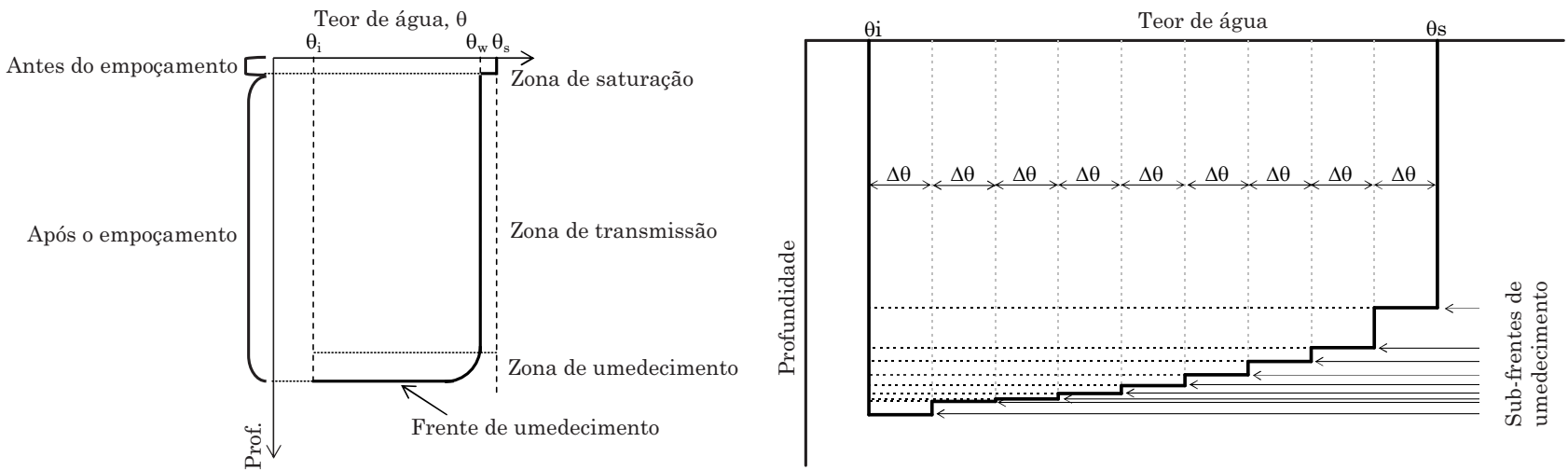

Figura 1. Perfil de umedecimento do solo considerado no GAML-c: teórico (a) e discretizado (b). 
no desenvolvimento do GAML-c: validade da equação de Darcy; perfil do solo homogêneo; e profundidade do solo infinita. No entanto, duas novas premissas foram consideradas: existência de várias subfrentes de umedecimento abruptas; e potencial matricial em cada subfrente de umedecimento constante no tempo e ao longo da profundidade.

Descreveu-se o movimento das subfrentes de umedecimento, tomando como exemplo o perfil de umidade apresentado na figura 2. Considerou-se a primeira subfrente de umedecimento, que se deslocou pelo perfil, entre as profundidades (a) e (b), elevando o teor de água do solo de $\theta_{\mathrm{i}}$ até $\theta_{\mathrm{w}}$, tomado igual a $\theta_{\mathrm{s}}$. Nesse caso, o cálculo de $\Delta \theta$ foi feito pela equação 4 .

Como a primeira subfrente de umedecimento, considerada na figura 2 , elevou o teor de água do solo para $\theta_{\mathrm{s}}$, o potencial matricial $\left(\psi\left(\theta_{\mathrm{w}}\right)\right)$ nessa subfrente (profundidade b) foi igual a $\psi_{\mathrm{b}}$. Aplicando-se a equação de Green-Ampt-Mein-Larson para essa frente, teve-se:

$$
\mathrm{Ti}_{1}=\mathrm{K}_{\mathrm{eq} 1}\left(1+\frac{\psi_{\mathrm{f}}}{\mathrm{L}_{1}}\right)
$$

em que: $\mathrm{Ti}_{1}=$ taxa de infiltração provocada pela primeira subfrente, $\mathrm{L} \mathrm{T}^{-1} ; \mathrm{K}_{\mathrm{eq} 1}=$ condutividade hidráulica equivalente do solo entre a superfície e a profundidade $\mathrm{L}_{1}, \mathrm{~L} \mathrm{~T}^{-1}$; e $\mathrm{L}_{1}=$ profundidade da primeira subfrente de umedecimento, $\mathrm{L}$.

Pela figura 2, percebeu-se que a lâmina parcial infiltrada $\left(\mathrm{I}_{\text {parcial }}\right)$ foi igual a:

$$
I_{\text {parcial }}=I_{0}+I_{0}=L_{0}\left(\theta_{\mathrm{s}}-\theta_{\mathrm{i}}\right)+\left(\mathrm{L}_{1}-\mathrm{L}_{0}\right)\left(\theta_{\mathrm{s}}-\theta_{\mathrm{i}}\right)
$$

em que: $\mathrm{I}_{1}=$ lâmina infiltrada após o empoçamento em razão do deslocamento da primeira subfrente, $L$; $\mathrm{I}_{0}=$ lâmina infiltrada antes do empoçamento, $\mathrm{L} ; \mathrm{e} \mathrm{L}_{0}$ = profundidade da frente de umedecimento no momento do empoçamento, $\mathrm{L}$.

$\mathrm{O}$ valor de $\mathrm{L}_{1}$ da equação 6 pôde ser aproximado por $\frac{I_{\text {parcial }}}{(3 \Delta \theta)}$. Substituindo-se esse valor na equação 6 , fazendo $\operatorname{Ti}(\mathrm{t})=\frac{\mathrm{dI}(\mathrm{t})}{\mathrm{dt}}$, e integrando-a com relação ao

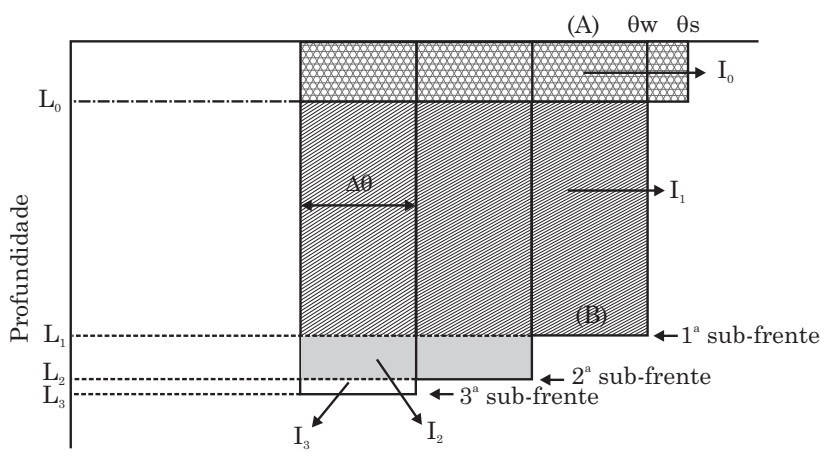

Figura 2. Perfil de umidade em um instante qualquer, após o empoçamento. tempo (t), nos intervalos te $t_{p}$ (Mein \& Larson, 1973), obteve-se a equação 8, que descreve a infiltração depois da completa saturação da superfície do solo, isto é, em $\mathrm{t}>\mathrm{t}_{\mathrm{p} \text { : }}$

$$
\mathrm{K}_{\text {eq1 }}\left(\mathrm{t}-\mathrm{t}_{\mathrm{p}}\right)=\mathrm{I}_{\text {parcial }}-\left[\psi\left(\theta_{\mathrm{w}}\right)\right](3 \Delta \theta) \ln \left[1+\frac{\mathrm{I}_{\text {parcial }}}{\left[\psi\left(\theta_{\mathrm{w}}\right)\right](3 \Delta \theta)}\right]
$$

Inserindo-se o parâmetro de correção $\mathrm{t}_{\mathrm{s}}($ Mein \& Farrell, 1974), na equação 8, teve-se:

$$
\mathrm{K}_{\text {eq1 }}\left(\mathrm{t}-\mathrm{t}_{\mathrm{p}}+\mathrm{t}_{\mathrm{s}}\right)=\mathrm{I}_{\text {parcial }}\left[\psi\left(\theta_{\mathrm{w}}\right)\right](3 \Delta \theta) \ln \left[1+\frac{\mathrm{I}_{\text {parcial }}}{\left[\psi\left(\theta_{\mathrm{w}}\right)\right](3 \Delta \theta)}\right](9)
$$

em que $t_{\mathrm{s}}$ foi o tempo necessário para infiltrar a lâmina $\mathrm{I}_{0}$ sob saturação da camada superficial do solo, L. O valor de $t_{\mathrm{s}}$ foi calculado pela equação 8 , substituindose $\left(t-t_{p}\right)$ por $t_{s}$ e I por $I_{0}$.

Analisando-se as equações 7 e 9 , verificou-se que $\mathrm{K}_{\text {eq1 }}$ foi o único parâmetro desconhecido, necessário para a determinação de $\mathrm{I}_{1} \mathrm{e}$, consequentemente, de $\mathrm{L}_{1}$ e da lâmina parcial infiltrada em um tempo $t>t_{p}$ qualquer. Esse parâmetro pôde ser calculado por:

$$
\mathrm{K}_{\mathrm{eq1}}=\frac{\mathrm{L}_{0}+\left(\mathrm{L}_{1}-\mathrm{L}_{0}\right)}{\frac{\mathrm{L}_{0}}{\mathrm{~K}_{0}}+\frac{\mathrm{L}_{1}-\mathrm{L}_{0}}{\mathrm{~K}\left(\theta_{\mathrm{i}}+3 \Delta \theta\right)}}
$$

em que $\mathrm{K}\left(\theta_{\mathrm{i}}+3 \Delta \theta\right)$ foi a condutividade hidráulica do solo com teor de água $\theta_{\mathrm{i}}+3 \Delta \theta$.

Utilizando a mesma linha de raciocínio para a segunda subfrente teve-se:

$\mathrm{I}_{\text {parcial }}=\mathrm{I}_{0}+\mathrm{I}_{1}+\mathrm{I}_{2}$

$\mathrm{I}_{\text {parcial }}=\mathrm{L}_{0}\left(\theta_{\mathrm{s}}-\theta_{\mathrm{i}}\right)+\left(\mathrm{L}_{1}-\mathrm{L}_{0}\right)\left(\theta_{\mathrm{w}}-\theta_{\mathrm{i}}\right)+\left(\mathrm{L}_{2}-\mathrm{L}_{1}\right)\left(\theta_{\mathrm{i}}+2 \Delta \theta\right)$

em que: $\mathrm{I}_{2}=$ lâmina infiltrada, após o empoçamento, em razão do deslocamento da segunda subfrente, $\mathrm{L}$; $\mathrm{e}$ $\mathrm{L}_{2}=$ profundidade da segunda subfrente de umedecimento, $\mathrm{L}$.

$$
\begin{aligned}
& \mathrm{K}_{\mathrm{eq} 2}\left(\mathrm{t}-\mathrm{t}_{\mathrm{p}}+\mathrm{t}_{\mathrm{s}}\right)=\mathrm{I}_{\text {parcial }}-\left[\psi\left(\theta_{\mathrm{i}}+2 \Delta \theta\right)\right](2 \Delta \theta) \\
& \ln \left[1+\frac{\mathrm{I}_{\text {parcial }}}{\left[\psi\left(\theta_{\mathrm{i}}+2 \Delta \theta\right)\right](2 \Delta \theta)}\right]
\end{aligned}
$$

em que $\mathrm{K}_{\text {eq2 }}$ foi a condutividade hidráulica equivalente do solo situado entre a superfície e a profundidade $\mathrm{L}_{2}$, $\mathrm{L} \mathrm{T}^{-1}$, sendo calculado por:

$$
\mathrm{K}_{\mathrm{eq} 2}=\frac{\mathrm{L}_{0}+\left(\mathrm{L}_{1}-\mathrm{L}_{0}\right)+\left(\mathrm{L}_{2}-\mathrm{L}_{1}\right)}{\frac{\mathrm{L}_{0}}{\mathrm{~K}_{0}}+\frac{\mathrm{L}_{1}-\mathrm{L}_{0}}{\mathrm{~K}\left(\theta_{\mathrm{i}}+3 \Delta \theta\right)}+\frac{\mathrm{L}_{2}-\mathrm{L}_{1}}{\mathrm{~K}\left(\theta_{\mathrm{i}}+2 \Delta \theta\right)}}
$$

em que $K\left(\theta_{i}+2 \Delta \theta\right)$ foi a condutividade hidráulica do solo com teor de água $\theta_{\mathrm{i}}+2 \Delta \theta$.

A mesma linha de raciocínio pôde ser seguida para a terceira subfrente de umedecimento, ou para a n-ésima subfrente, o que levou às seguintes equações gerais: 


$$
\begin{aligned}
& \mathrm{I}_{\mathrm{pn}}=\sum_{\mathrm{i}=1}^{\mathrm{n}} \mathrm{I}_{\mathrm{i}} \\
& \mathrm{I}_{\mathrm{pn}}=\mathrm{L}_{0}\left(\theta_{\mathrm{s}}-\theta_{\mathrm{i}}\right)+\sum_{\mathrm{i}=1}^{\mathrm{n}}\left[\left(\mathrm{L}_{\mathrm{i}}+\mathrm{L}_{\mathrm{i}-1}\right)(\mathrm{nf}-\mathrm{i}+1) \Delta \theta\right]
\end{aligned}
$$

em que $I_{p n}$ foi a lâmina infiltrada parcial, após o empoçamento por causa do deslocamento da n-ésima subfrente de umedecimento, $\mathrm{L}$.

$$
\mathrm{K}_{\text {eqn }}=\frac{\mathrm{L}_{\mathrm{n}}}{\frac{\mathrm{L}_{0}}{\mathrm{~K}_{0}}+\sum_{\mathrm{i}=1}^{\mathrm{n}} \frac{\mathrm{L}_{\mathrm{i}}-\mathrm{L}_{\mathrm{i}-1}}{\mathrm{~K}\left[\theta_{\mathrm{i}}+(\mathrm{nf}-\mathrm{i}+1) \Delta \theta\right]}}
$$

em que $\mathrm{K}$ foi a condutividade hidráulica do solo não saturado.

$$
\begin{aligned}
\mathrm{K}_{\mathrm{eqn}} \mathrm{t}= & \mathrm{I}_{\mathrm{pn}}-\left[\psi\left(\theta_{\mathrm{i}}+(\mathrm{nf}-\mathrm{n}+1) \Delta \theta\right)\right][(\mathrm{nf}-\mathrm{n}+1) \Delta \theta] \\
& \ln \left[1+\frac{\mathrm{I}_{\text {parcial }}}{\left[\psi\left(\theta_{\mathrm{i}}+(\mathrm{nf}-\mathrm{n}+1) \Delta \theta\right)\right][(\mathrm{nf}-\mathrm{n}+1) \Delta \theta]}\right]
\end{aligned}
$$

Utilizaram-se as equações 14, 15 e 16 para o cálculo da infiltração, em razão do deslocamento de cada subfrente de umedecimento, fixado qualquer tempo $t>t_{p}$. Ressaltou-se que a simulação do deslocamento das subfrentes foi feita começando-se pela frente 1 , que elevou o solo à maior umidade.

A solução das três equações foi feita atribuindo-se valores para $\mathrm{I}_{\mathrm{i}}$, a fim de calcular $\mathrm{I}_{\mathrm{pn}}$ e $\mathrm{K}_{\mathrm{eqn}}$. Os valores de $\mathrm{I}_{\mathrm{pn}}$ e $\mathrm{K}_{\mathrm{eqn}}$ foram substituídos na equação 16 até que seus membros assumissem valores iguais.

Caso fosse considerado que o perfil de solo não atingisse a saturação após o empoçamento, ou seja $\theta_{\mathrm{w}}<\theta_{\mathrm{s}}$, deveria se utilizar a equação 5 para o cálculo de $\Delta \theta$. Além disso, na simulação da primeira subfrente de umedecimento, o potencial matricial $\left(\psi_{\mathrm{f}}\right)$ foi $\psi\left(\theta_{\mathrm{w}}\right)$, e não $\psi_{b}$. Os demais procedimentos continuaram sendo feitos da mesma maneira.

\section{Cálculo dos potenciais matriciais na frente de umedecimento e da condutividade hidráulica do solo}

O potencial matricial foi calculado por meio das equações 17 e 18 (Brooks \& Corey, 1964):

$$
\begin{gathered}
\theta(\psi)=\theta_{\mathrm{r}}+\left(\theta_{\mathrm{s}}-\theta_{\mathrm{r}}\right)\left[\frac{\psi_{\mathrm{b}}}{\psi}\right]^{\lambda}, \quad|\psi|>\left|\psi_{\mathrm{b}}\right| \\
\theta(\psi)=\theta_{\mathrm{s}},|\psi| \leq\left|\psi_{\mathrm{b}}\right|
\end{gathered}
$$

em que: $\psi_{\mathrm{b}}=$ potencial matricial de entrada de ar, $\mathrm{cm} ; \psi=$ potencial matricial, $\mathrm{cm} ; \lambda=$ índice de distribuição de tamanho de poros, adimensional; $\theta(\psi)$ $=$ teor de água do solo no potencial matricial $\mathrm{y}, \mathrm{cm}^{3}$ $\mathrm{cm}^{-3} ; \theta_{\mathrm{r}}=$ teor de água residual do solo, $\mathrm{cm}^{3} \mathrm{~cm}^{-3} ;$ e $\theta_{\mathrm{s}}$ $=$ teor de água do solo saturado, $\mathrm{cm}^{3} \mathrm{~cm}^{-3}$.

A condutividade hidráulica do solo não saturado $(\mathrm{K}(\theta))$ foi obtida pela equação de Burdine (Alexander \& Skaggs, 1986):

$$
\mathrm{K}(\theta)=\mathrm{K}(\theta(\psi))=\mathrm{K}_{0}\left[\frac{\psi_{\mathrm{b}}}{\psi(\theta)}\right]^{2+3 \lambda}
$$

\section{Avaliação do modelo}

A avaliação consistiu em determinar, em três testes experimentais, a lâmina infiltrada e taxa de infiltração da água sob chuva simulada, em perfis de Latossolo Vermelho-Amarelo, acondicionados em colunas de PVC com $20 \mathrm{~cm}$ de diâmetro e $78 \mathrm{~cm}$ de altura útil (Figura 3). A análise granulométrica do solo é apresentada no quadro 1 . Com os dados da curva de retenção de água no solo, foram ajustados modelos de curva de retenção de Brooks \& Corey (1964), obtendo-se os valores de $\psi_{\mathrm{b}}, \lambda$ e $\theta_{\mathrm{r}}$ apresentados no quadro 2 em conjunto com as seguintes características físicas dos perfis de solo: taxa de infiltração estável (Tie); condutividade hidráulica do solo saturado $\left(\mathrm{K}_{0}\right)$; massa específica do solo $\left(\mathrm{d}_{\mathrm{a}}\right)$; massa específica de partículas $\left(\mathrm{d}_{\mathrm{p}}\right)$; umidade inicial do solo $\left(\theta_{\mathrm{i}}\right)$; umidade da zona de transmissão $\left(\theta_{\mathrm{w}}\right)$; e umidade de saturação do solo $\left(\theta_{\mathrm{s}}\right)$.

Aplicou-se chuva simulada com intensidade constante sobre cada perfil de solo contido nas colunas de PVC, coletando todo o escoamento superficial produzido (Figura 3). Foi utilizado um simulador estacionário de bicos múltiplos e oscilantes, construído conforme modelo do National Soil Erosion Research Laboratory. Antes de se iniciar a aplicação de água, a superfície do solo era coberta com manta de tecido sintético altamente permeável (bidim), a fim de minimizar os efeitos do selamento superficial. As intensidades de precipitação ( $\left.i_{p}\right)$ aplicadas nos três testes experimentais foram iguais a 486,442 e $398 \mathrm{~mm} \mathrm{~h}^{-1}$.

A umidade do solo foi monitorada em diversas profundidades ao longo do tempo de realização dos testes experimentais. Para tanto, foi necessário que cada módulo de PVC tivesse sua parede perfurada para

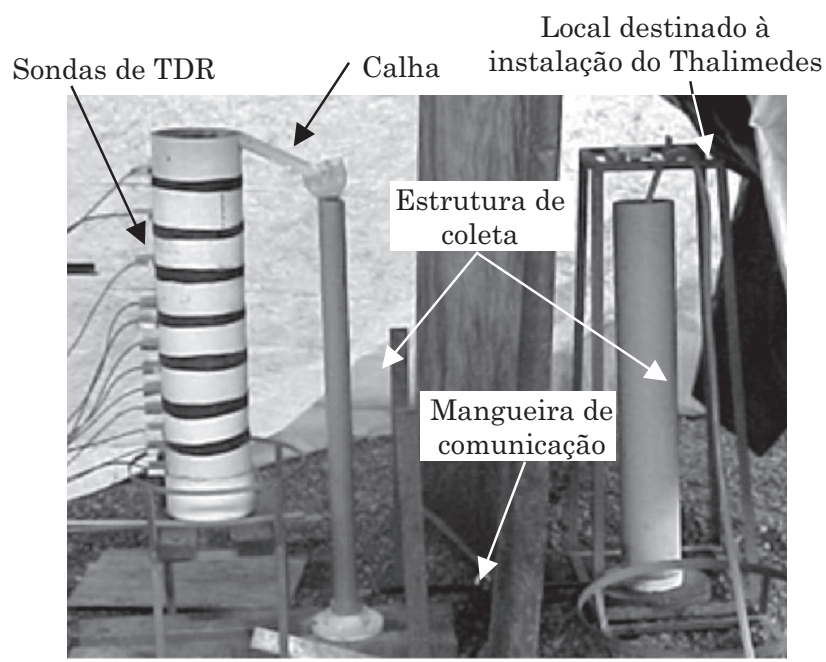

Figura 3. Disposição da coluna de PVC e da estrutura de coleta, durante o experimento. 
Quadro 1. Análise granulométrica do Latossolo Vermelho-Amarelo utilizado

\begin{tabular}{|c|c|c|c|c|c|}
\hline Areia grossa & Areia fina & Silte & Argila & Textura & Estrutura \\
\hline 13 & 10 & 7 & 70 & Muito argilosa & forte pequena/granular \\
\hline
\end{tabular}

Quadro 2. Características físicas do Latossolo Vermelho-Amarelo utilizado nos experimentos

\begin{tabular}{|c|c|c|c|}
\hline Característica física & Teste 1 & Teste 2 & Teste 3 \\
\hline Condutividade hidráulica do solo saturado $-\mathrm{K}_{0}\left(\mathrm{~mm} \mathrm{~h}^{-1}\right)^{(1)}$ & 112,1 & 129,5 & 106,0 \\
\hline Taxa de infiltração estável - Tie $\left(\mathrm{mm} \mathrm{h}^{-1}\right)^{(2)}$ & 130,3 & 72,5 & 107,6 \\
\hline Massa específica aparente do solo $-\mathrm{d}_{\mathrm{a}}\left(\mathrm{g} \mathrm{cm}^{-3}\right)^{(3)}$ & 1,05 & 1,06 & 1,07 \\
\hline Massa específica de partículas - $\mathrm{d}_{\mathrm{p}}\left(\mathrm{g} \mathrm{cm}^{-3}\right)^{(3)}$ & 2,289 & 2,289 & 2,289 \\
\hline Umidade inicial do solo $-\theta_{\mathrm{i}}\left(\mathrm{cm}^{3} \mathrm{~cm}^{-3}\right)^{(4)}$ & 0,327 & 0,320 & 0,318 \\
\hline Umidade da zona de transmissão $-\theta_{\mathrm{w}}\left(\mathrm{cm}^{3} \mathrm{~cm}^{-3}\right)^{(5)}$ & 0,521 & 0,509 & 0,524 \\
\hline Umidade de saturação $-\theta_{\mathrm{s}}\left(\mathrm{cm}^{3} \mathrm{~cm}^{-3}\right)^{(6)}$ & 0,541 & 0,537 & 0,534 \\
\hline Pressão de borbulhamento $-\psi_{\mathrm{b}}(\mathrm{cm})$ & 8,7 & 9,1 & 9,1 \\
\hline Índice de distribuição do tamanho de poros $-\lambda$ & 0,4032 & 0,4032 & 0,4032 \\
\hline Umidade residual $-\theta_{\mathrm{r}}\left(\mathrm{cm}^{3} \mathrm{~cm}^{-3}\right)$ & 0,237 & 0,240 & 0,241 \\
\hline
\end{tabular}

(1) Método do permeâmetro de carga constante; ${ }^{(2)}$ Obtida ao final dos testes experimentais; ${ }^{(3)}$ De acordo com Embrapa (1997); ${ }^{(4)}$ Método padrão de estufa e TDR; ${ }^{(5)}$ Método do TDR; e ${ }^{(6)}$ Igual à porosidade total do solo

a inserção de sondas de TDR (Figura 3). Sondas de TDR foram inseridas paralelas à superfície do solo nas profundidades de $6,16,26,36,41,46,51,56,61$, 66,71 e $76 \mathrm{~cm}$. Essas foram utilizadas tanto para medir o teor de água inicial e o final do solo quanto para determinar periodicamente os teores de água do perfil do solo, durante a realização dos testes experimentais. Ressalta-se que o teor de água inicial também foi determinado pelo método padrão de estufa, retirando-se amostras no momento do adensamento do solo dentro das colunas.

O escoamento superficial gerado durante a aplicação de chuva simulada foi conduzido a uma estrutura de coleta por meio da calha instalada na parte superior da coluna de PVC (Figura 3). Essa estrutura foi composta por dois reservatórios comunicantes por meio de uma mangueira flexível. $\mathrm{O}$ primeiro reservatório destinava-se a coletar toda a água escoada, enquanto no segundo foi instalado um equipamento medidor de nível de água, denominado Thalimedes, que registrava e armazenava a altura da lâmina de água dentro da estrutura de coleta. Dessa forma, pôde-se determinar a variação temporal da lâmina de água infiltrada (I) e taxa de infiltração (Ti), durante o tempo de condução dos testes experimentais. Os testes foram encerrados no momento em que ocorreu a saída de água por um dreno localizado na parte inferior da coluna de PVC. Considerou-se que a taxa de infiltração estável da água no solo (Tie) foi atingida, após ser verificada que a taxa de variação do nível d'água dentro da estrutura de coleta tornou-se constante.

\section{Avaliação}

Para o emprego do GAML-c, consideraram-se dois valores distintos de condutividade hidráulica do solo saturado: $\mathrm{K}_{0}$ obtido com o emprego do permeâmetro de carga constante e taxa de infiltração estável (Tie). Nas simulações, também foram consideradas duas condições distintas de umidade do perfil de solo, uma tomando o valor de $\theta_{\mathrm{S}}$ como teor de água máximo que o solo atingia após o empoçamento; e outra tomando $\mathrm{q}_{\mathrm{w}}$ como esse valor. Assim sendo, foram feitas quatro simulações com o GAML-c, para cada teste experimental, a fim de verificar quais os parâmetros que forneceriam melhores estimativas da taxa de infiltração, da lâmina infiltrada e do perfil de umidade do solo: condutividade hidráulica igual a $\mathrm{K}_{0}$ e umidade máxima igual a $\theta_{\mathrm{S}}(\mathrm{KS})$; condutividade hidráulica igual a $K_{0}$ e umidade máxima igual a $\theta_{\mathrm{w}}(\mathrm{KW})$; condutividade hidráulica igual à Tie e umidade máxima igual a $\theta_{\mathrm{s}}(\mathrm{TS})$; e condutividade hidráulica igual à Tie e umidade máxima igual a $\theta_{\mathrm{w}}$ (TW).

Para fins de comparação, foram feitas também simulações, empregando-se o modelo de GAML em sua forma original. As avaliações do desempenho do GAML e do GAML-c foram feitas por meio do cálculo de índices estatísticos que correlacionam os valores experimentais com os valores estimados pelo modelo, a saber: índice de confiança modificado - c' (adaptado de Camargo \& Sentelhas, 1997) e coeficiente de eficiência ajustado - E' (Legates \& McCabe Jr., 1999). Ressaltou-se que os índices estatísticos foram aplicados para avaliar a perfomance do GAML-c, para 
a estimativa tanto da lâmina infiltrada quanto da taxa de infiltração ao longo do tempo.

O índice de confiança modificado (c') foi calculado pelo produto entre o coeficiente de correlação $(r)$ e índice de concordância modificado (d'); seus valores variaram de zero, para nenhuma concordância, a um, para a concordância perfeita. No quadro 3 , são apresentados os critérios de avaliação do desempenho de modelos quanto ao valor de c'.

$$
d^{\prime}=1-\frac{\sum_{i=1}^{J}\left|O_{i}-E_{i}\right|}{\sum_{i=1}^{J}\left(\left|E_{i}-\bar{O}\right|+\left|O_{i}-\bar{O}\right|\right)}
$$

em que: $J=$ número de observações; $\mathrm{O}=$ valor observado experimentalmente; $\mathrm{E}$ = valor estimado pelo modelo; e $\overline{\mathrm{O}}=$ média dos valores observados experimentalmente.

O coeficiente de eficiência ajustado (E'), calculado pela equação 21 , variou de $-\infty$ a 1 , com os maiores valores indicando melhor performance.

$$
E^{\prime}=1-\frac{\sum_{i=1}^{J}\left|O_{i}-E_{i}\right|}{\sum_{i=1}^{J}\left|O_{i}-\bar{O}\right|}
$$

\section{RESULTADOS E DISCUSSÃO}

Na figura 4 são apresentadas as curvas simuladas de Ti e I ao longo do tempo, bem como os seus valores experimentais nos três testes realizados. No quadro 4, evidenciam-se os coeficientes estatísticos E' e c' e o desempenho das simulações realizadas na estimativa de I e Ti, feitas nos três testes experimentais realizados. Considerando-se apenas o GAML-c, verificou-se, de maneira geral, que as quatro formas de sua aplicação estimaram satisfatoriamente os valores de $\mathrm{Ti}$ e I, excetuando-se o segundo teste experimental. Nesse, observou-se desempenho inferior da simulação que utilizou a Tie como condutividade hidráulica do solo e $\mathrm{q}_{\mathrm{w}}$ como umidade da zona de transmissão (TW), e também da que fez uso de $\mathrm{K}_{0}$ como condutividade hidráulica e $\mathrm{q}_{\mathrm{s}}$ como umidade da zona de transmissão (KS). A simulação TW tendeu a subestimar Ti e I enquanto a KS, superestimar. Na simulação KS, do segundo teste experimental, os valores negativos de E' indicou a ineficiência das simulações.

Quadro 3. Análise do desempenho do modelo com base no índice de confiança modificado - c'

\begin{tabular}{cccc}
\hline Valor de c' & Desempenho & Valor de c' & Desempenho \\
\hline$>0,85$ & Ótimo & 0,51 a 0,60 & Sofrível \\
0,76 a 0,85 & Muito bom & 0,41 a 0,50 & Mau \\
0,66 a 0,75 & Bom & $\leq 0,40$ & Péssimo \\
0,61 a 0,65 & Mediano & & \\
\hline
\end{tabular}

Observou-se, ainda, que as simulações que consideraram um mesmo valor para umidade da zona de transmissão $\left(\theta_{\mathrm{w}}\right.$ ou $\left.\theta_{\mathrm{s}}\right)$, independentemente do parâmetro adotado como condutividade hidráulica, tiveram desempenhos muito próximos. O terceiro teste experimental foi bastante ilustrativo dessa situação, pois as curvas simuladas (Figura 4) para as simulações TW e KW quase se sobrepuseram, ocorrendo o mesmo para TS e KS; tal fato deveu-se à grande proximidade entre os valores de $\mathrm{K}_{0} \mathrm{e}$ Tie no teste.

Nenhuma das simulações com o GAML-c apresentou sempre os melhores resultados para todos os testes experimentais. A simulação que utilizou em conjunto os parâmetros Tie e $\theta_{\mathrm{s}}$ (TS) apresentou boas estimativas, indicando que a Tie pode ser usada para representar a condutividade hidráulica do perfil do solo. Nessas simulações, o desempenho nunca foi inferior a "Bom" para Ti e "Muito Bom" para I; o valor de E' foi sempre superior a 0,5 .

Notou-se que o modelo GAML em sua forma original não foi adequado para estimativa de Ti e I, apenas no segundo teste experimental (valores negativos para E'). Nos demais testes, o desempenho dele foi aceitável e comparável às melhores simulações feitas com o GAML-c, indicando que esse foi adequado para a estimativa da infiltração, comparativamente ao modelo original de GAML. Nesse sentido, com base nos resultados observados, recomendou-se, para estimar a infiltração, o uso do valor da Tie como representativo de $\mathrm{K}_{0}$, em substituição ao valor determinado usando o método do permeâmetro de carga constante (PCC), corroborando Cecílio et al. (2007) e Zonta et al. (2012a,b).

A aplicação do PCC alterou a estrutura das amostras de solo, promovendo sua compactação (Marques et al., 2008), sendo, portanto, parcialmente responsável por altos coeficientes de variação na determinação de $\mathrm{K}_{0}$, também relatados por Mesquita et al. (2003), Mesquita \& Moraes (2004), Gubiani et al. (2010), Pedron et al., (2011) e Hickmann et al. (2012). Na mesma linha dessa discussão, Scherpinski et al. (2010) apresentaram que a determinação em campo da Tie provê menores coeficientes de variação que o $\mathrm{K}_{0}$ determinado com o permeâmetro, o que levou a reforçar a recomendação de uso da Tie.

Com relação aos parâmetros $\mathrm{K}_{0} \mathrm{e}$ Tie, percebeu-se que, no segundo teste experimental, o valor de $\mathrm{K}_{0}$ foi maior que o da Tie, quando o esperado era justamente o contrário. $\mathrm{O}$ maior valor de $\mathrm{K}_{0}$ deveu-se em parte à maior condutividade hidráulica, determinada pelo método do permeâmetro de carga constante, apresentada pelo solo contido em dois dos módulos que formavam a coluna. Uma possível causa consistiu na ocorrência de perturbação e rearranjo dos agregados, quando da desmontagem da coluna de solo e retirada desses módulos, fato também relatado por Marques et al. (2008). Também pode ter havido fluxo preferencial da água pela interface entre o solo e as paredes dos módulos. Destacou-se que pode ter havido 

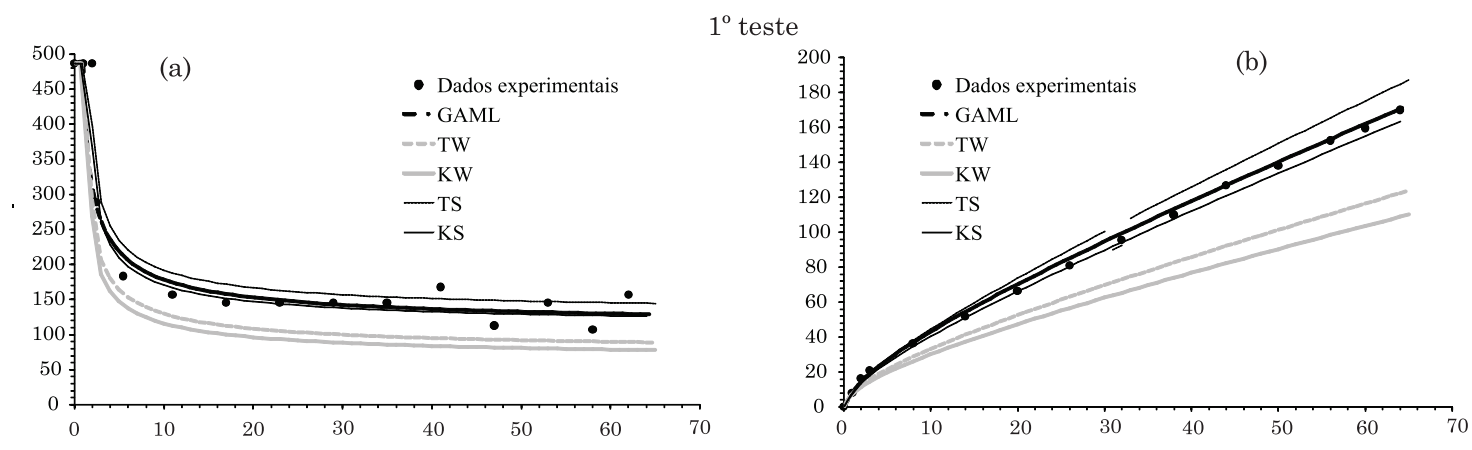

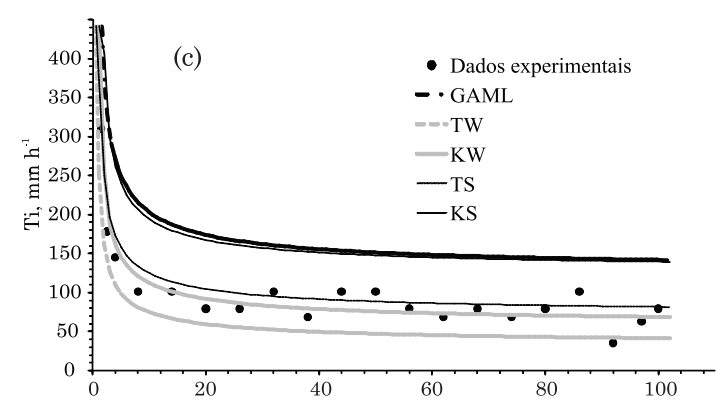

$2^{\circ}$ teste
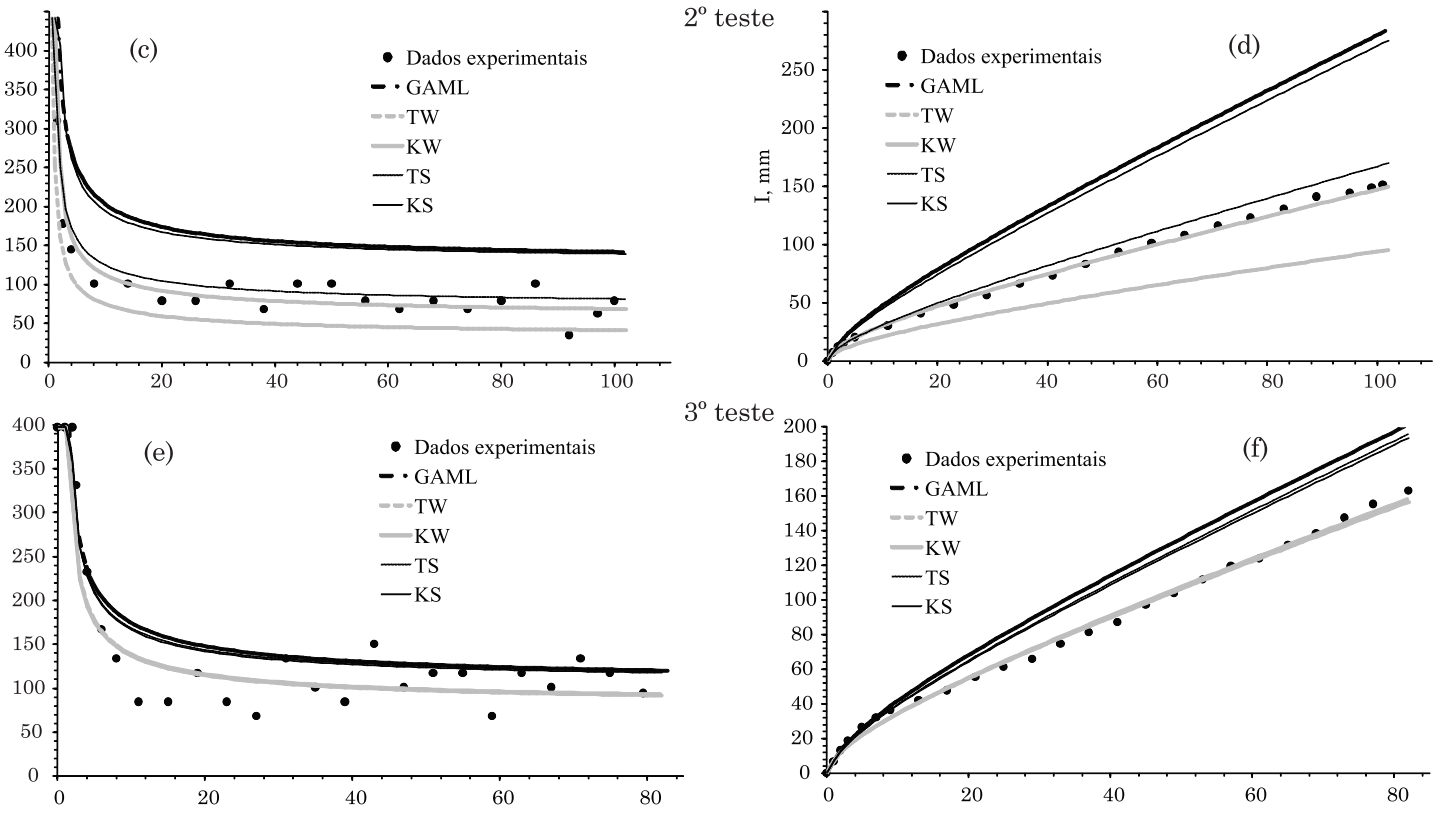

stemes

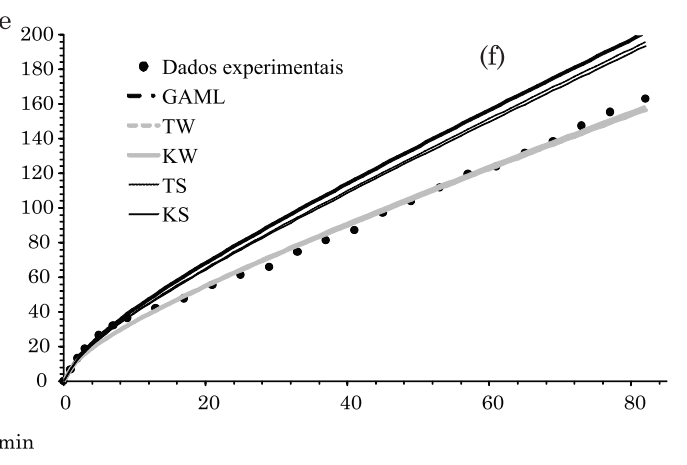

Figura 4. Taxas de infiltração (a) e lâminas infiltradas (b) medidas e estimadas no $1^{\circ}$ teste; (c) e (d), no $2^{\circ}$ teste; (e) e (f), $3^{\text {o }}$ teste.

Quadro 4. Coeficientes estatísticos calculados para as estimativas da lâmina infiltrada e da taxa de infiltração feitas pelo GAML original e pelo GAML-c nos três testes experimentais

\begin{tabular}{|c|c|c|c|c|c|c|c|c|c|c|}
\hline \multirow{2}{*}{$\begin{array}{l}\text { Coeficiente } \\
\text { estatístico }\end{array}$} & \multicolumn{2}{|c|}{ GAML } & \multicolumn{2}{|c|}{ Simulação TW } & \multicolumn{2}{|c|}{ Simulação KW } & \multicolumn{2}{|c|}{ Simulação TS } & \multicolumn{2}{|c|}{ Simulação KS } \\
\hline & $\mathbf{I}$ & $\mathbf{T i}$ & $\mathbf{I}$ & $\mathbf{T i}$ & $\mathbf{I}$ & $\mathbf{T i}$ & $\mathbf{I}$ & $\mathbf{T i}$ & $\mathbf{I}$ & $\mathbf{T i}$ \\
\hline \multicolumn{11}{|c|}{$1^{\circ}$ teste experimental } \\
\hline $\mathrm{E}^{\prime}$ & 0,96 & 0,72 & 0,54 & 0,40 & 0,39 & 0,27 & 0,83 & 0,78 & 0,94 & 0,77 \\
\hline$c^{\prime}$ & 0,98 & 0,79 & 0,73 & 0,68 & 0,64 & 0,62 & 0,92 & 0,86 & 0,97 & 0,85 \\
\hline Desempenho & Ótimo & M. bom & Bom & Bom & Mediano & Mediano & Ótimo & Ótimo & Ótimo & Ótimo \\
\hline \multicolumn{11}{|c|}{$2^{\circ}$ teste experimental } \\
\hline $\mathrm{E}^{\prime}$ & $-0,53$ & $-0,19$ & 0,32 & 0,17 & 0,95 & 0,77 & 0,80 & 0,66 & $-0,41$ & $-0,23$ \\
\hline$c^{\prime}$ & 0,51 & 0,21 & 0,59 & 0,59 & 0,97 & 0,87 & 0,91 & 0,80 & 0,53 & 0,21 \\
\hline Desempenho & Sofrível & Péssimo & Sofrível & Sofrível & Ótimo & Ótimo & Ótimo & M. bom & Sofrível & Péssimo \\
\hline \multicolumn{11}{|c|}{$3^{\circ}$ teste experimental } \\
\hline$E^{\prime}$ & 0,50 & 0,52 & 0,93 & 0,58 & 0,93 & 0,57 & 0,57 & 0,55 & 0,60 & 0,55 \\
\hline$c^{\prime}$ & 0,78 & 0,66 & 0,96 & 0,72 & 0,96 & 0,71 & 0,81 & 0,68 & 0,82 & 0,69 \\
\hline Desempenho & M. bom & Bom & Ótimo & Bom & Ótimo & Bom & M. bom & Bom & M. bom & Bom \\
\hline
\end{tabular}

KS: condutividade hidráulica igual à condutividade hidráulica do solo saturado $\left(\mathrm{K}_{0}\right)$ e umidade máxima igual à umidade de saturação $\left(\theta_{\mathrm{s}}\right)$; KW: condutividade hidráulica igual a $\mathrm{K}_{0}$ e umidade máxima igual à umidade da zona de transmissão $\left(\theta_{\mathrm{w}}\right)$; TS: condutividade hidráulica igual à taxa de infiltração estável (Tie) e umidade máxima igual a $\theta_{\mathrm{s}}$; TW: condutividade hidráulica igual a Tie e umidade máxima igual a $\theta_{\mathrm{w}}$; I: lâmina infiltrada; Ti: taxa de infiltração; E': coeficiente de eficiência ajustado; e c': índice de confiança modificado 
subestimativa do valor da Tie nesse teste, uma vez que essa foi calculada com base na média dos últimos valores experimentais de Ti.

Nas figuras 5, 6 e 7, são apresentados os perfis de umidade medidos e estimados pelas simulações feitas com a utilização do GAML-c, nos três testes experimentais do LVA. Notou-se nas simulações relativas aos três testes experimentais que, fixado um valor qualquer de tempo, houve pequena diferença nas profundidades simuladas de cada subfrente de umedecimento. Tal resultado justificou-se pelo LVA possuir alta macroporosidade e comportamento de
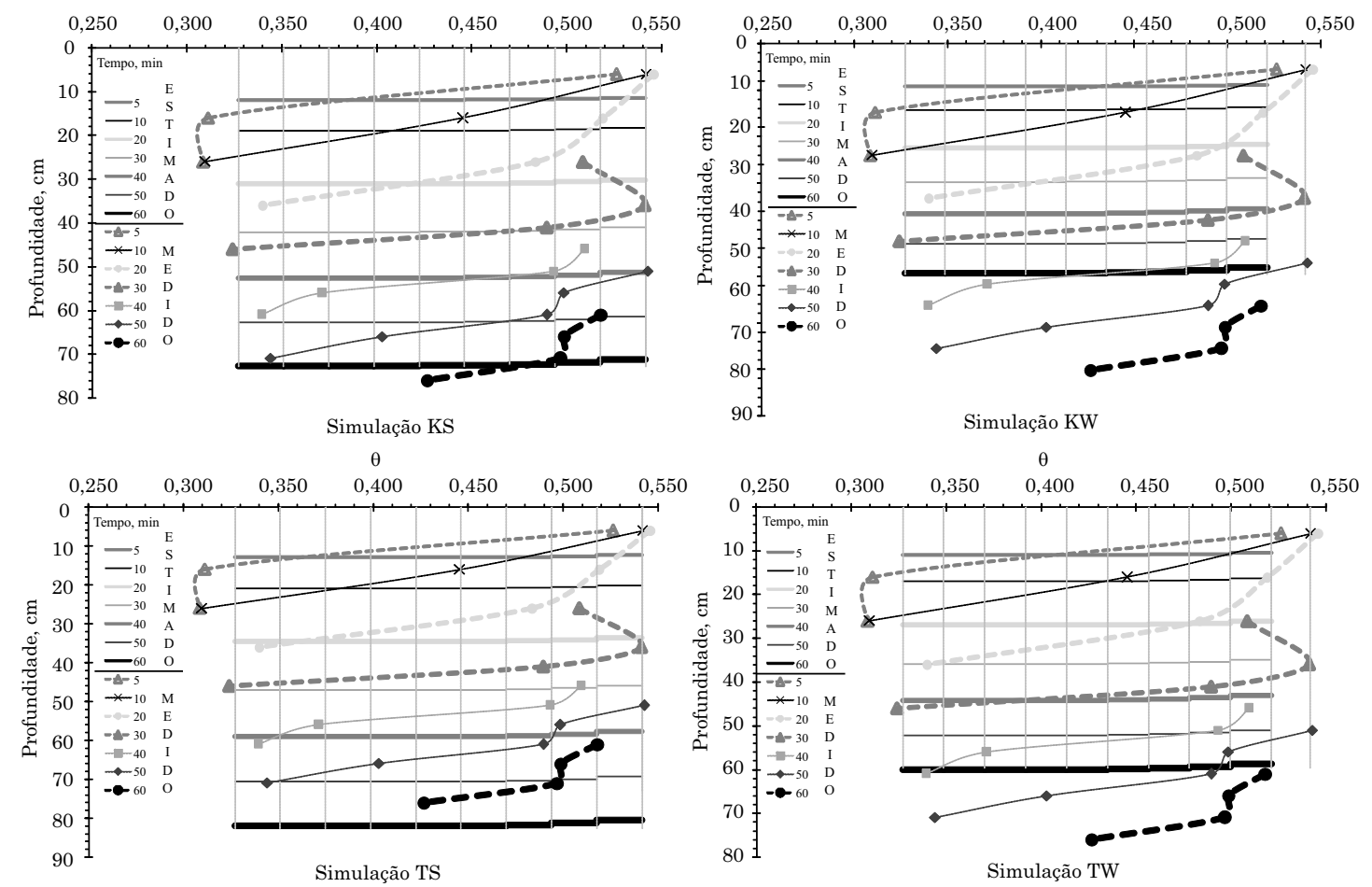

Figura 5. Perfis de umidade medidos e estimados com o GAML-c no $1^{\circ}$ teste experimental.
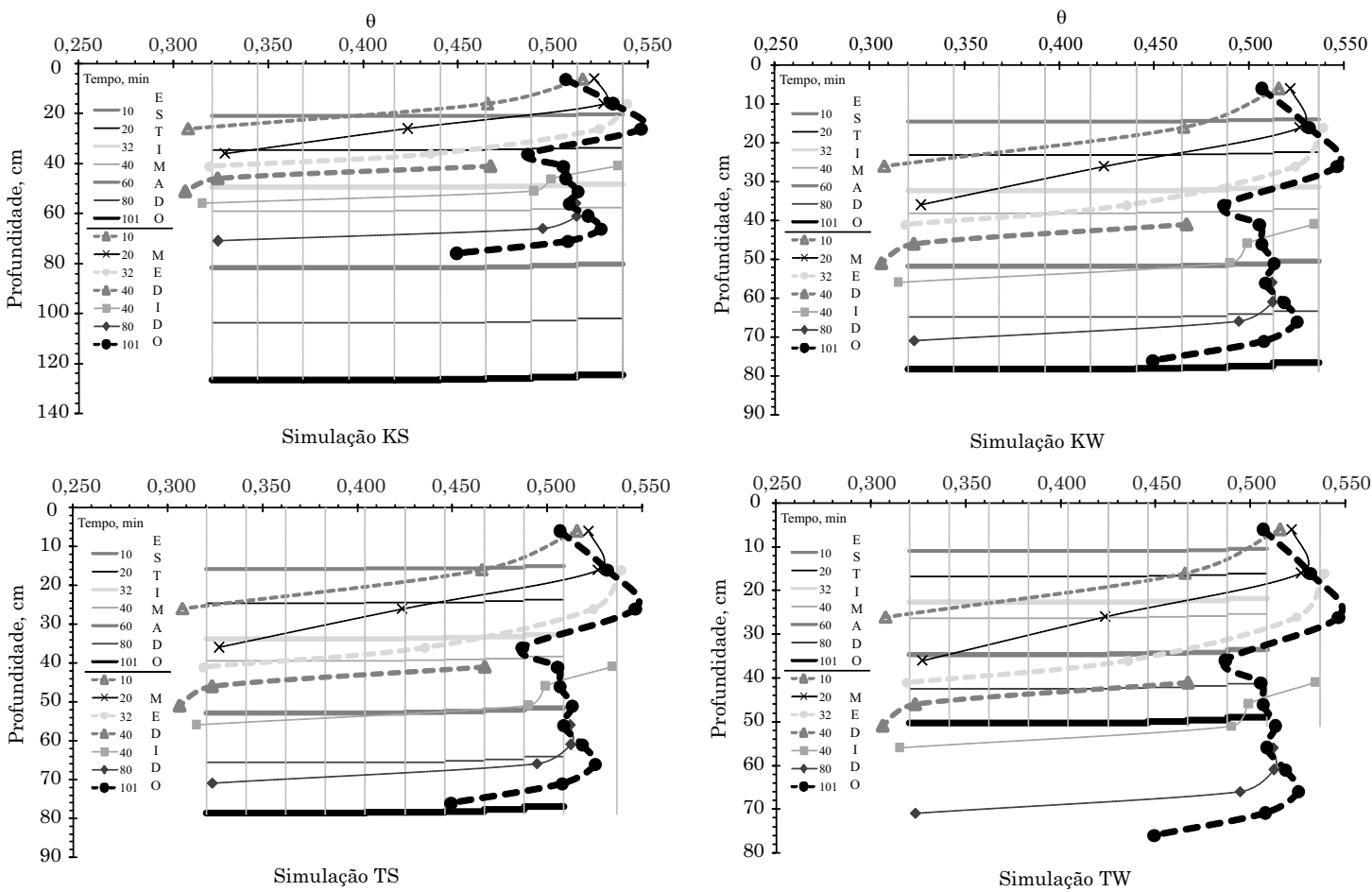

Figura 6. Perfis de umidade medidos e estimados com o GAML-c no $2^{\circ}$ teste experimental. 

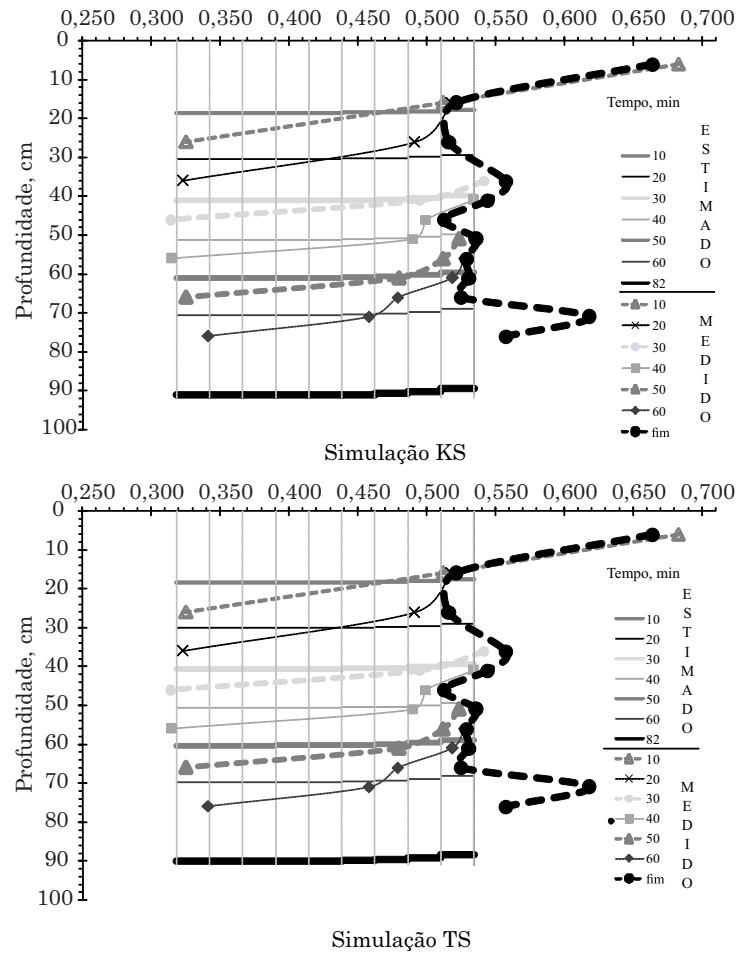
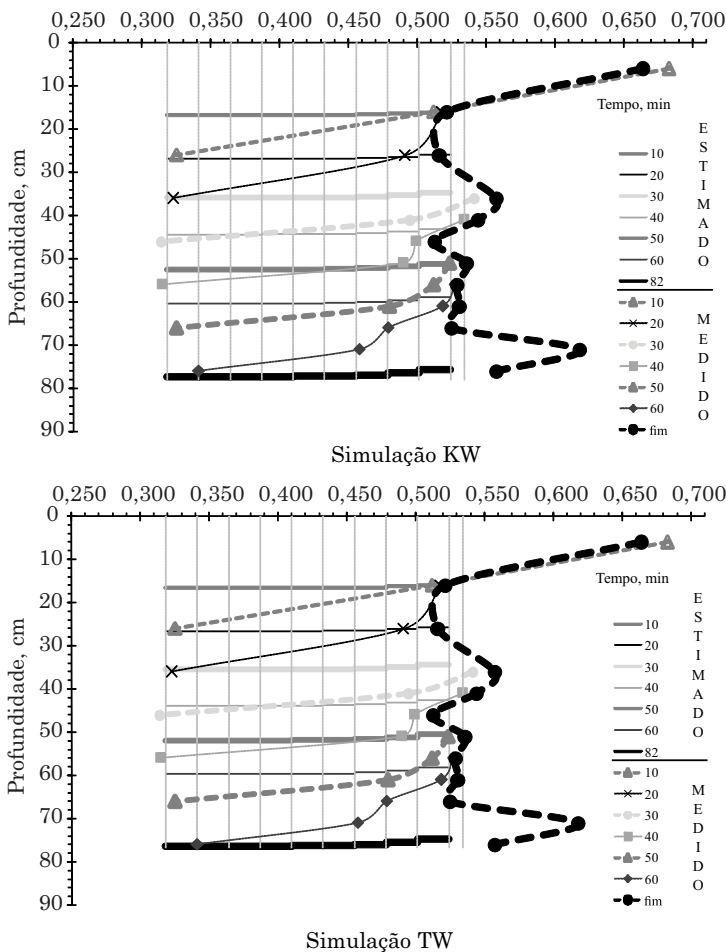

Figura 7. Perfis de umidade medidos e estimados com o GAML-c no $3^{\circ}$ teste experimental.

retenção de água semelhante ao de solos arenosos, acarretando pequena variação do teor de água na frente de umedecimento ao longo da profundidade.

De modo geral, as simulações que consideraram que o solo atingia apenas a umidade $\theta_{\mathrm{w}}$ após o tempo de empoçamento (KW e TW), apresentaram menores estimativas da profundidade das subfrentes de umedecimento, quando comparadas às que utilizaram $\theta_{\mathrm{s}}$. Isso ocorreu por causa dos menores valores de condutividade hidráulica equivalente do perfil do solo, provenientes da queda da umidade de $\theta_{\mathrm{s}}$ para $\theta_{\mathrm{w}}$. Porém, no terceiro teste experimental, nas profundidades $6 \mathrm{e}$ $71 \mathrm{~cm}$, observaram-se dois valores de umidade medida extremamente altos, extrapolando, inclusive, a umidade de saturação do solo. Tais valores se devem a erros nas leituras feitas com o TDR, não representando valores reais da umidade.

Com relação ao perfil de umidade, as simulações que utilizaram o valor de $\theta_{\mathrm{S}}$ como o teor de água que o perfil do solo atingiu após o tempo de empoçamento (TS e KS) acabaram por estimar maiores profundidades das subfrentes de umedecimento. Esse fato foi em razão do maior peso que o parâmetro tomado como condutividade hidráulica do solo saturado ( $\mathrm{K}_{0}$ ou Tie) passou a ter no cálculo da condutividade hidráulica equivalente do solo.

Não houve simulação que melhor estimasse o perfil de umidade nos três testes experimentais. No primeiro teste experimental, o perfil de umidade foi mais bem estimado pela simulação que utilizou $\mathrm{K}_{0} \operatorname{com} \theta_{\mathrm{S}}(\mathrm{KS}) \mathrm{e}$ Tie $\operatorname{com} \theta_{\mathrm{s}}$ (TS). No segundo, houve melhor estimativa do perfil de umidade com as simulações que utilizaram $\mathrm{K}_{0} \operatorname{com} \theta_{\mathrm{w}}(\mathrm{KW})$ e Tie com $\theta_{\mathrm{S}}(\mathrm{TS})$. Finalmente, no terceiro teste experimental, as combinações $\mathrm{K}_{0}$ com $\theta_{\mathrm{w}}(\mathrm{KW})$ e Tie $\operatorname{com} \theta_{\mathrm{w}}(\mathrm{TW})$ simularam melhor o perfil de umidade. Assim como ocorrido para a estimativa de Ti e I, no geral, os melhores perfis foram estimados pela simulação TS, indicando que o GAML-c, com essa configuração, pode ser usado para simular o perfil de umidade do solo durante a infiltração, de modo semelhante às equações propostas em trabalho de Wang et al. (2009).

O modelo GAML-c foi capaz de contornar o problema levantado por Wang et al. (2003), relativo à incapacidade de GA e GAML em estimar a distribuição de umidades no perfil do solo, durante a ocorrência da infiltração.

Embora não tenha havido uma simulação única que apresentasse melhores estimativas de $\mathrm{Ti}, \mathrm{I}$ e do perfil de umedecimento, as simulações TW e TS, que utilizaram a Tie, tiveram bom desempenho na maior parte dos testes, reforçando a ideia anterior a respeito do uso desse parâmetro como representativo da condutividade hidráulica do perfil de solo.

\section{CONCLUSÕES}

1. O modelo desenvolvido (GAML-c) foi capaz de estimar o perfil de umidade do Latossolo VermelhoAmarelo utilizado neste estudo. 
2. O GAML-c aplicado, utilizando-se a taxa de infiltração estável como parâmetros de entrada (simulação TW), resultou em melhores estimativas da infiltração.

3. O desempenho do GAML-c nas simulações TW, TS e KW foi melhor que o modelo original de GreenAmpt-Mein-Larson.

\section{LITERATURA CITADA}

ALEXANDER, L. \& SKAGGS, R.W. Predicting unsaturated hydraulic conductivity from the soil water characteristic. Trans. Am. Soc. Agric. Eng., 29:176-184, 1986.

BROOKS, R.H. \& COREY, A.T. Hydraulic properties of porous media. Fort Collins, Colorado State University, 1964. 26p. (Hydrologic Paper \#3)

CAMARGO, Â.P. \& SENTElhas, P.C. Avaliação do desempenho de diferentes métodos de estimativa da evapotranspiração potencial no Estado de São Paulo. R. Bras. Agrometeo., 5:89-97, 1997.

CECÍLIO, R.A.; MARTINEZ, M.A.; PRUSKI, F.F.; SILVA, D.D. \& ATAÍDE, W.F. Substituição dos parâmetros do modelo de Green-Ampt-Mein-Larson para a estimativa da infiltração em alguns solos do Brasil. R. Bras. Ci. Solo, 31:1141-1151, 2007.

EMPRESA BRASILEIRA DE PESQUISA AGROPECUÁRIA - EMBRAPA. Centro Nacional de Pesquisa de Solos. Manual de métodos de análise de solo. 2.ed. Rio de Janeiro, 1997. 212p.

GUBIANI, P.I.; REINERT, D.J.; REICHERT, J.M.; GELAIN, N.S. \& MINELLA, J.P.G. Permeâmetro de carga decrescente associado a programa computacional para a determinação da condutividade hidráulica do solo saturado. R. Bras. Ci. Solo, 34:993-997, 2010.

HICKMANN, C.; COSTA, L.M.; SCHAEFER, C.E.G.R.; FERNANDES, R.B.A. \& ANDRADE, C.L.T. Atributos físico-hídricos e carbono orgânico de um Argissolo após 23 anos de diferentes manejos. R. Caatinga, 25:128136, 2012.

KALE, R.V. \& SAHOO, B. Green-Ampt infiltration models for varied field conditions: A review. Water Res. Manage., 25:3505-3536, 2011.

LEGATES, D.R. \& McCABE JR., G.J. Evaluating the use of "goodness-of-fit" measures in hydrologic and hydroclimatic model validation. Water Res. Res., 35:233241, 1999.
MARQUES, J.D.O.; TEIXEIRA, W.G.; REIS, A.M.; CRUZ JUNIOR, O.F. \& MARTINS, G.C. Avaliação da condutividade hidráulica do solo saturada utilizando dois métodos de laboratório numa topossequência com diferentes coberturas vegetais no Baixo Amazonas. Acta Amaz., 38:193-206, 2008.

MEIN, R.G. \& FARRELL, D.A. Determination of wetting front suction in the Green-Ampt equation. Soil Sci. Soc. Am. Proc., 38:399-417, 1974.

MEIN, R.G. \& LARSON, C.L. Modeling infiltration during a steady rain. Water Res. Res., 9:384-394, 1973.

MESQUiTA, M.G.B.F.; MORAES, S.O. \& CORRENTE, J.E. Caracterização estatística de variáveis físicas do solo. Acta Sci. Agron., 25:35-44, 2003.

MESQUITA, M.G.B.F. \& MORAES, S.O. A dependência entre a condutividade hidráulica saturada e atributos físicos do solo. Ci. Rural, 34:963-969, 2004.

NEARING, M.A.; WEI, H.; STONE, J.J.; PIERSON, F.B.; SPAETH, K.E.; WELTZ, M.A.; FLANAGAN, D.C. \& HERNANDEZ, M. A rangeland hydrology and erosion model. Trans. Am. Soc. Agric. Biol. Eng., 54:1-8, 2011.

PEDRON, F.A.; FINK, J.R.; RODRIGUES, M.F. \& AZEVEDO, A.C. Condutividade e retenção de água em Neossolos e saprolitos derivados de arenito. R. Bras. Ci. Solo, 35:1253-1262, 2011.

RUCKER, D. A coupled electrical resistivity-infiltration model for wetting front evaluation. Vadose Zone J., 8:383-388, 2009.

SCHERPINSKI, C.; URIBE-OPAZO, M.A.; VILAS BOAS, M.A.; SAMPAIO, S.C. \& JOHANN, J.A. Variabilidade espacial da condutividade hidráulica e da infiltração da água no solo da água no solo. Acta Sci. Agron., 32:7-13, 2010.

WANG, J.; HE, J. \& CHEN, H. Assessment of groundwater contamination risk using hazard quantification, a modified DRASTIC model and groundwater value, Beijing Plain, China. Sci. Total Environ., 432:216-226, 2012.

WANG, Q.; HORTON, R. \& SHAO, M. Algebraic model for one-dimensional infiltration and soil water distribution. Soil Sci., 168:671-676, 2003.

WANG, Q.; HORTON, R. \& FAN, J. An analytical solution for one-dimensional water infiltration and redistribution in unsaturated soil. Pedosphere, 19:104-110, 2009.

ZONTA, J.H.; MARTINEZ, M.A.; PRUSKI, F.F.; SILVA, D.D. \& SANTOS, M.R. Modelagem da infiltração em solos com encrostamento superficial. Parte I: Modelo GAML para solos estratificados. R. Bras. de Eng. Agríc. Amb., 16:461-470, 2012a.

ZONTA, J.H.; MARTINEZ, M.A.; SILVA, D.D.; PRUSKI, F.F. \& SANTOS, M.R. Modelagem da infiltração em solos com encrostamento superficial. Parte II: Condutividade hidráulica variando no tempo. R. Bras. Eng. Agríc. Amb., 16:471-479, 2012b. 